\title{
The outcomes of intestinal resection during debulking surgery for ovarian cancer
}

\author{
Serdar Gökay Terzioğlu', Murat Özgür Kılıç ${ }^{1}$, Nilüfer Çetinkaya², Eralp Baser², Tayfun Güngör², Cevdet Adıgüzel ${ }^{3}$
}

\begin{abstract}
Objective: To evaluate the clinical and surgical outcomes of intestinal resection during primary debulking surgery for ovarian cancer.

Material and Methods: This retrospective study was conducted at Zekai Tahir Burak Women's Health Training and Research Hospital between 2009 and 2013. The patients who underwent intestinal resection during debulking surgery for stage 3 ovarian cancer were included in the analysis. Data regarding patient age, body mass index, tumor histology, disease stage, the site of intestinal resection, all postoperative complications, duration of intensive care unit admission and hospital stay were collected and analyzed.

Results: A total of 22 patients with a mean age of 53.4 years were included in the study. Optimal cytoreduction was achieved in $14(63 \%)$ patients. Transverse colectomy was the most common type of intestinal resection (63\%). The most common postoperative complication was transfusion of blood products $(63 \%)$. No postoperative mortality was observed.

Conclusion: Intestinal resection is a crucial part of debulking surgery for advanced ovarian cancer, with acceptable complication rates. Despite the limited number of patients, the results obtained from the present study are comparable with previous reports.

Keywords: Cytoreductive surgery, debulking surgery, intestinal resection, morbidity, ovarian cancer
\end{abstract}

\section{INTRODUCTION}

Ovarian cancer is the most lethal and the second most frequently diagnosed cancer among all gynecologic malignancies (1). Most ovarian cancers are epithelial neoplasms and tend to spread along peritoneal surfaces. Therefore, patients with ovarian cancer are often diagnosed at advanced disease stages with an average 5 -year survival rate of approximately $30 \%(2,3)$. Cytoreductive surgery followed by chemotherapy is the mainstay therapeutic approach and is considered to be the largest contributor of survival in advanced ovarian cancer (4). However, cytoreductive or debulking surgery is associated with high postoperative morbidity rates. There are several factors affecting morbidity rates such as age, general status of the patient, the presence of comorbidities, patient volume of the medical center, subtype of the tumor, and the extent of surgery (5). Intestinal surgery is usually indicated as part of debulking surgery to provide optimal tumor reduction among these patients, and is also responsible for increased postoperative morbidity $(6,7)$. Besides being a part of debulking surgery, intestinal surgery may be also needed for iatrogenic bowel injury or intestinal obstruction. In addition, bowel resection is often required for abdominal and pelvic recurrences and in palliation of intestinal obstruction (8).

'Clinic of General Surgery, Numune Training and Research Hospital, Ankara, Turkey ${ }^{2}$ Clinic of Gynecologic Oncology, Zekai Tahir Burak Women's Health Training and Research Hospital, Ankara, Turkey ${ }^{3}$ Clinic of Gynecologic Oncology, Numune Training and Research Hospital, Adana, Turkey

Address for Correspondence Murat Özgür Kılı̧̧ e-mail:murat05ozgur@hotmail.com

Received: 15.01.2016 Accepted: 14.03.2016

CCopyright 2017 by Turkish Surgical Association

Available online at www.turkjsurg.com
In this study, we aimed to evaluate therapeutic outcomes and morbidity of intestinal resection during debulking surgery for stage III ovarian cancer.

\section{MATERIAL AND METHODS}

\section{Patients}

A total of 22 patients who underwent intestinal resection during debulking surgery for stage 3 ovarian carcinoma between 2009 and 2013 were included in this retrospective study. The ethics committee of Zekai Tahir Burak Women's Health Training and Research Hospital approved the study protocol. Informed consent was not taken from the patients due to the retrospective nature of the study. The data including patient age and body mass index (BMI), histology and stage of the tumor, the type of intestinal surgery, all postoperative complications, duration of intensive care unit (ICU) admission and hospital stay were collected from medical charts of the patients. The patients who only underwent appendectomy or intestinal surgery without resection were excluded from the study. 


\section{Study Design}

All operations were performed by a single gynecological oncologist and a single general surgery team. Mechanical bowel cleansing and antibiotic prophylaxis were routinely administered to all patients on the day before surgery. All operations were performed via a standard midline abdominal incision. Gastrointestinal stapling devices were usually used for intestinal anastomosis. Rectosigmoid resection was performed in en bloc retroperitoneal approach method. In this technique as described earlier, the rectosigmoid colon was separated from the peritoneum and left pelvic wall by routine steps, and was divided using gastrointestinal stapling device (9). Optimal debulking was considered as the largest diameter of residual tumor equal to or less than $1 \mathrm{~cm}$ at the end of the surgery.

The Statistical Package for the Social Sciences (IBM Corp.; Armonk, NY, USA) version 21 was used for statistical analysis. Descriptive analysis was presented as mean $\pm \mathrm{SD} /$ percentage for continuous variables and number/percentage for categorical variables. $\mathrm{P}<0.05$ was considered to be statistically significant.

\section{RESULTS}

The data of 22 consequent patients (mean age 53.4 years) who underwent debulking surgery with intestinal resection for stage III ovarian cancer were analyzed. Primary debulking was the unique indication for surgery. Optimal debulking surgery was achieved in $14(63.7 \%)$ patients. Intestinal resection was performed to all patients because of tumoral spread to intestines. The most common type of intestinal resection was transverse colectomy $(14,63.7 \%)$. Anastomosis with an end-to-end technique was performed in the majority of patients $(20,90.9 \%)$. Colostomy was preferred in two patients (9.1\%) who underwent low anterior resection for rectal involvement. As an indicator for blood loss, hemoglobin $(\mathrm{Hb})$ change was calculated by subtracting postoperative $\mathrm{Hb}$ from preoperative $\mathrm{Hb}$ levels. The mean $\mathrm{Hb}$ change was $3.1 \mathrm{gr} / \mathrm{dL}$. The demographic and clinical characteristics of the patients, surgical data, and pathological findings are presented in Table 1.

At least one postoperative complication was observed in 19 (86.4\%) patients. The most common postoperative complication was transfusion of blood products, with an incidence of $63.6 \%$. Two patients developed postoperative ileus; however, both had ability to pass flatus on the fifth day of the operation. Re-operation within the postoperative period was required in two patients. One of those patients underwent re-laparatomy for anastomotic leak on the $6^{\text {th }}$ day of the operation, and colostomy was performed. The second patient had uncontrolled intestinal fistula, and thus the fistula tract was surgically removed on the $14^{\text {th }}$ day of the surgery. All postoperative complications are presented in Table 2.

Pelvic abscess developed in one patient, and was successfully treated with antibiotherapy. The patient with pulmonary embolism was also treated medically with intravenous heparin. No mortality was observed postoperatively.
Table 1. Clinical characteristics of the patients who underwent intestinal resection during primary debulking surgery

\begin{tabular}{|c|c|}
\hline Characteristics & n (\%) \\
\hline Age (y) & $53.4 \pm 9.3$ \\
\hline BMI & $30.5 \pm 3.7$ \\
\hline Albumin (gr/dL) & $3.2 \pm 0.6$ \\
\hline Preoperative $\mathrm{Hb}$ (gr/dL) & $11.6 \pm 1.0$ \\
\hline Postoperative $\mathrm{Hb}$ (gr/dL) & $8.4 \pm 0.9$ \\
\hline $\mathrm{Hb}$ change & $3.1 \pm 0.9$ \\
\hline \multicolumn{2}{|l|}{ Histological variant } \\
\hline Serous & $9(40.9 \%)$ \\
\hline Kruckenberg & $5(22.7 \%)$ \\
\hline Endometriod & $3(13.6 \%)$ \\
\hline Mucinous & $3(13.6 \%)$ \\
\hline NET & $2(9 \%)$ \\
\hline
\end{tabular}

Type of intestinal resection

Transverse colon resection 14 (63.7\%)

Sigmoid colon resection $\quad 5(22.7 \%)$

lleum resection $4(18.1 \%)$

Low anterior resection 2 $2(9 \%)$

Operating time $(\mathrm{min}) \quad 228.4 \pm 30.6$

Oral intake (h) $\quad 6.0 \pm 2.4$

ICU admission (d) $\quad 4.8 \pm 2.5$

Hospital stay (d)

$12.3 \pm 2.6$

Histological variant, type of intestinal resection, optimal debulking, and hemorrhage were presented as $n(\%)$; the other variables were presented as mean $\pm S D$.

y: year; h: hour; min: minute; d: day; BMl: Body Mass Index; Hb: hemoglobin; NET: neuroendocrine tumor; ICU: intensive care unit

Table 2. Postoperative short- and long-term complications

Complications n (\%)

Transfusion of blood products 14 (63.6)

Surgical site infection 6 (27.3)

Atelectasis 4 (18.2)

Wound dehiscence $3(13.6)$

lleus $2(9.1)$

Pulmonary embolism $1(4.5)$

Gastrointestinal fistula $1(4.5)$

Pelvic abscess

1 (4.5)

\section{DISCUSSION}

Primary optimal debulking surgery for ovarian cancer is traditionally defined as residual tumor less than one centimeter (10). However, debulking surgery has been recently classified as complete (without residual disease) and incomplete (with a residual disease at the end of the surgery) at the Gynecological Cancer Inter Group consensus conference in 2010 (11). Com- 
plete resection of all macroscopic disease has been shown to be highly correlated with prolongation of the survival (12-15). Although the completeness of debulking surgery is the single indicator of survival of the patients with ovarian cancer, stage and histologic subtype of the tumor also have significant prognostic effects (5). Unfortunately, only one third of ovarian cancers can be detected at early stages and most patients have stage 3 or 4 disease at the time of diagnosis (16-18).

An extensive resection containing pelvic surgery, pelvic and abdominal lymphadenectomy, and abdominal surgery is usually performed during debulking surgery. Intestinal surgery is usually indicated for optimal debulking in the treatment of ovarian cancer in 20 to $100 \%$ of the patients (19). The potential role of intestinal resection on morbidity and oncological outcomes have been studied in many studies $(20,21)$. There is a consensus on the positive prognostic impact of intestinal surgery in the surgical treatment of advanced ovarian cancer. Also, optimal debulking surgery was shown to reduce postoperative ileus and ascites (22). Despite these advantages, surgery-related morbidity remains a major concern of debulking surgery for most surgeons. In debulking surgery, morbidity associated with intestinal surgery has been reported with an incidence rate of up to $20 \%$ (21). In our department, maximal debulking surgery including bowel resection is the standard surgical approach because of its promoting impacts on the survival.

In the literature, bowel resection during debulking surgery was reported up to $23 \%(23,24)$. Tamussino et al. $(23)$ reported that rectosigmoid resection was the most common intestinal resection during primary surgical treatment of ovarian cancer while colostomy was performed in only $2 \%$ of the patients. In contrast, the most common type of intestinal resection was transverse colectomy, and colostomy was only needed in $9 \%$ of the patients in the present study.

Clark et al. (25) reported that at least one or more perioperative complications occurred in approximately one third of the patients who underwent cytoreductive surgery with intestinal resection in their patient group. They also reported that the most common perioperative complications were cardiopulmonary events and small bowel obstruction. Fauci et al. (26) found that comorbidity was highly associated with readmission within 30 days of discharge, and small bowel obstruction/ileus was the most common reason for this entity. Cai et al. (27) also reported the major complication rate as $22 \%$ in their debulking surgery series. In that study, the patients who underwent bowel resection had a significantly higher median survival as compared with the patients with suboptimal debulking. In addition, the major complications such as ileus, intestinal fistula, and urinary tract fistula were found to be similar between those groups, indicating that morbidity following debulking surgery with intestinal resection seemed acceptable. In the present study, at least one or more complications occurred in 19 out of 22 patients. This rate may be considered as higher in comparison to previous studies. However, it should be noted that there is not a standard classification of morbidities in those studies, in which either minor or major complications were reported. On the other hand, all complications from mild to severe were reported in our study. In addition, colonic resections which are most frequently related to postoperative morbidity were more common in our case series, in comparison to small bowel resections. The leading morbidity was related to transfusion of blood products, with an incidence of $63 \%$. However, complications related to intestinal resection, such as intestinal fistula, pelvic abscess, and ileus developed in the minority of patients. Similarly, Morice et al. (28) found transfusion rate to be $39 \%$ in patients with debulking surgery.

Type of intestinal resection may be considered to be associated with the development of postoperative complications. Colonic resections are generally believed to be related to higher morbidity rates more than small bowel resections. Bristow et al. (24) reported that transverse colectomy contributed to optimal cytoreductive surgery with an acceptable morbidity rate. In that study, gastrointestinal fistula was reported in $5.3 \%$ of the patients. In our study, two major complications directly related to intestinal resection (one postoperative acute complete bowel obstruction and one intestinal fistula) were observed during the follow-up period, consistent with the literature $(20,21)$.

It is well known that patients with advanced ovarian cancer are usually in the old or mid-old age population and have accompanying systemic diseases that result in increased postoperative complication rates. Additionally, aggressive debulking surgery in old patients were reported to be associated with increase in postoperative mortality (29). In our study, the mean age was 53 years, and approximately $30 \%$ of the patients had at least one accompanying systemic disease. However, no mortality was observed within the postoperative period.

Mean intensive care unit admission was 4.8 days in our study. Bristow et al. (24) reported that the mean duration of intensive care unit admission was 2.5 days. This may be explained with the high comorbidity rate in our study population.

\section{CONCLUSION}

Optimal debulking surgery is the mainstay treatment of advanced ovarian cancer, and is highly correlated with patient survival. Intestinal resection is one of the main components of this radical procedure, with acceptable complication rates. Despite the limited number of patients, the results obtained from the present study are comparable with previous reports.

Ethics Committee Approval: Ethics committee approval was received for this study from the ethics committee of Zekai Tahir Burak Women's Health Training and Research Hospital.

Informed Consent: Informed consent was not received due to the retrospective nature of the study.

Peer-review: Externally peer-reviewed.

Author Contributions: Concept - S.G.T., M.Ö.K., T.G.; Design - S.G.T., N.Ç.; Supervision - M.Ö.K., E.B., T.G.; Resource -M.Ö.K., C.A.; Materials S.G.T., N.Ç., E.B.; Data Collection and/or Processing - E.B., C.A.; Analysis and/or Interpretation - S.G.T., M.Ö.K.; Literature Search - M.Ö.K., N.Ç.; Writing Manuscript - M.Ö.K.; Critical Reviews -S.G.T., T.G.

Conflict of Interest: No conflict of interest was declared by the authors.

Financial Disclosure: The authors declared that this study has received no financial support. 


\section{REFERENCES}

1. Siegel R, Ward E, Brawley O, Jemal A. Cancer statistics, 2011: the impact of eliminating socioeconomic and racial disparities on premature cancer deaths. CA Cancer J Clin 2011; 61: 212-236. [CrossRef]

2. Jayson GC, Kohn EC, Kitchener HC, Ledermann JA. Ovarian cancer. Lancet 2014; 384: 1376-1388. [CrossRef]

3. Hankinson SE, Danforth KN. Ovarian Cancer. Schottenfeld D, Fraumeni J. Cancer epidemiology and prevention. $3^{\text {rd }}$ edn. New York, NY: Oxford University Press. 2006: 1013-1026. [CrossRef]

4. Crandon AJ, Obermair A. Advanced cytoreductive surgery: Asia Pacific perspective. Gynecol Oncol 2009; 114: 15-21. [CrossRef]

5. Ghaemmaghami F, Hassanzadeh M, Karimi-Zarchi M, ModariGilani M, Behtash A, Mousavi N. Centralization of ovarian cancer surgery: do patients benefit? Eur J Gynaecol Oncol 2010; 31:429433

6. Venesmaa P, Ylikorkala O. Morbidity and mortality associated with primary and repeat operations for ovarian cancer. Obstet Gynecol 1992; 79: 168-172. [CrossRef]

7. Castaldo TW, Petrilli ES, Ballon SC, Lagasse LD. Intestinal operations in patients with ovarian carcinoma. Am J Obstet Gynecol 1981; 139: 80-84. [CrossRef]

8. Takahashi $\mathrm{O}$, Tanaka T. Intestinal surgery in advanced ovarian cancer. Curr Opin Obstet Gynecol 2007; 19: 10-14. [CrossRef]

9. Obermair A, Hagenauer S, Tamandl D, Clayton RD, Nicklin JL, Perrin LC, et al. Safety and efficacy of low anterior en bloc resection as part of cytoreductive surgery for patients with ovarian cancer. Gynecol Oncol 2001; 83: 115-120. [CrossRef]

10. Hoskins WY, McGuire WP, Brady MF, Homesley HD, Creasman WT, Berman $M$, et al. The effect of diameter of largest residual disease on survival after primary cytoreductive surgery in patients with suboptimal residual epithelial ovarian carcinoma. Am J Obstet Gynecol 1994; 170: 974-979. [CrossRef]

11. Stuart GC, Kitchener H, Bacon M, duBois A, Friedlander M, Ledermann J, et al. 2010 Gynecologic Cancer InterGroup (GCIG) consensus statement on clinical trials in ovarian cancer: report from the Fourth Ovarian Cancer Consensus Conference. Int J Gynecol Cancer 2011; 21: 750-755. [CrossRef]

12. Randall TC, Rubin SC. Cytoreductive surgery for ovarian cancer Surg Clin North Am 2001; 81: 871-883. [CrossRef]

13. Hoskins WJ. Epithelial ovarian carcinoma: principles of primary surgery. Gynecol Oncol 1994; 55: 91-96. [CrossRef]

14. du Bois A Reuss A, Pujade-Lauraine E, Harter P, Ray-Coquard I, Pfisterer J. Role of surgical outcome as prognostic factor in advanced epithelial ovarian cancer: a combined exploratory analysis of 3 prospectively randomized phase 3 multicenter trials: by the Arbeitsgemeinschaft Gynaekologische Onkologie Studiengruppe Ovarialkarzinom (AGO-OVAR) and the Groupe d'Investigateurs Nationaux Pour les Etudes des Cancers de l'Ovaire (GINECO) Cancer 2009; 115: 1234-1244. [CrossRef]

15. Vergote I, du Bois A, Amant F, Heitz F, Leunen K, Harter P. Neoadjuvant chemotherapy in advanced ovarian cancer: On what do we agree and disagree? Gynecol Oncol 2013; 128: 6-11. [CrossRef]

16. Tanaka Y, Terai Y, Tanabe A, Sasaki H, Sekijima T, Fujiwara S, et al. Prognostic effect of epidermal growth factor receptor gene mutations and the aberrant phosphorylation of Akt and ERK in ovarian cancer. Cancer Biol Ther 2011; 11: 50-57. [CrossRef]

17. Bhat RA, Chia YN, Lim YK, Yam KL, Lim C, Teo M. Survival impact of secondary cytoreductive surgery for recurrent ovarian cancer in an Asian population. Oman Med J 2015; 30: 344-352. [CrossRef]

18. Minig L, Zorrero C, Iserte PP, Poveda A. Selecting the best strategy of treatment in newly diagnosed advanced-stage ovarian cancer patients. World J Methodol 2015; 5: 196-202.

19. Chéreau E, Ballester M, Lesieur B, Selle F, Coutant C, Rouzier R, et al. Complications of radical surgery for advanced ovarian cancer. Gynecol Obstet Fertil 2011; 39: 21-27. [CrossRef]

20. Estes JM, Leath CA $3^{\text {rd }}$, Straughn JM Jr, Rocconi RP, Kirby TO, Huh WK, et al. Bowel resection at the time of primary debulking for epithelial ovarian carcinoma: outcomes in patients treated with platinum and taxane-based chemotherapy. J Am Coll Surg 2006; 203: 527-532. [CrossRef]

21. Miller J, Proietto A. The place of bowel resection in initial debulking surgery for advanced ovarian cancer. Aust N Z J Obstet Gynaecol 2002; 42: 535-537. [CrossRef]

22. Pecorelli S, Favalli G. Surgical versus chemical upfront debulking in advanced ovarian cancer. Int J Gynecol Cancer 2000; 10: 12-15. [CrossRef]

23. Tamussino KF, Lim PC, Webb MJ, Lee RA, Lesnick TO. Gastrointestinal surgery in patients with ovarian cancer. Gynecol Oncol 2001; 80: 79-84. [CrossRef]

24. Bristow RE, Peiretti M, Zanagnolo V, Salani R, Giuntoli RL $2^{\text {nd }}$, Mag gioni A. Transverse colectomy in ovarian cancer surgical cytoreduction: operative technique and clinical outcome. Gynecol Oncol 2008; 109: 364-369. [CrossRef]

25. Clark RM, Growdon WB, Wiechert A, Boruta D, Del Carmen M, Goodman AK, et al. Patient, treatment and discharge factors associated with hospital readmission within 30 days after surgical cytoreduction for epithelial ovarian carcinoma. Gynecol Oncol 2013; 130: 407-410. [CrossRef]

26. Fauci JM, Schneider KE, Frederick PJ, Wilding G, Consiglio J, Sutton $A L$, et al. Assessment of risk factors for 30-day hospital readmission after surgical cytoreduction in epithelial ovarian carcinoma. Int J Gynecol Cancer 2011; 21: 806-810. [CrossRef]

27. Cai HB, Zhou YF, Chen HZ, Hou HY. The role of bowel surgery with cytoreduction for epithelial ovarian cancer. Clin Oncol (R Coll Radiol) 2007; 19: 757-762. [CrossRef]

28. Morice P, Dubernard G, Rey A, Atallah D, Pautier P, Pomel C, et al. Results of interval debulking surgery compared with primary debulking surgery in advanced stage ovarian cancer. J Am Coll Surg 2003; 197: 955-963. [CrossRef]

29. Ries LAG, Melbert D, Krapcho M, Stinchcomb DG, Howlader N, Horner MJ, et al. SEER Cancer Statistics Review. National Cancer Institute; Bethesda. MD: 2008. 1975-2005 